\title{
A Study of the Visualization Tool for Computer Science Majors' Capability Assessment
}

\author{
Feng Ye, Yong Chen, and Qian Huang
}

\begin{abstract}
IT industry burgeoning, more and more enterprises and universities pay attention to the comprehensive ability of computer science majors. However, the existing assessment method giving priority to test scores, could not greatly demonstrate computer science majors' capability and their development approaches, with drawbacks of serious one-sidedness, limitation and low perceptual intuition. Correspondingly, it's difficult to teach students according to their aptitude or interests. Moreover, the current research works show that this research field still requires theoretical foundations, appropriate models, effective tools, in-depth experimentations and practical implementations. In order to solve this problem, the paper proposes an index system of students' for evaluating computer science majors' ability, designs and implements the relevant visualization software of capability assessment based on dynamic radar charts and jitterplot, and then illustrates the application of this visual software through case studies. Based on the visualization tool, it has achieved good results in practical teaching.
\end{abstract}

Index Terms-Visualization tool, radar chart, jitterplot, capability assessment.

\section{INTRODUCTION}

IT industry burgeoning, more and more enterprises and universities are deeply aware that the capability of computer science majors is closely related to the future of the whole industry. Under such a background, enterprises and universities both at home and abroad pay more attention to the comprehensive ability of computer science majors, including knowledge acquisition, innovation, team collaboration, language expression and communication, programming, scientific research, etc. However, the existing assessment method giving priority to test scores, lacks the comprehensive mechanism to fully demonstrate computer science majors' capability and their development approaches, with drawbacks of serious one-sidedness, limitation and low perceptual intuition. Correspondingly, it's difficult to teach students according to their aptitude or interests. Therefore, it is very significant and valuable to study how to evaluate computer

Manuscript received March 12, 2018; revised August 3, 2018. This work was supported in part by the National Natural Science Foundation of China [grant number No.61300122]; 2017 Jiangsu Province Postdoctoral Research Funding Project[grant number 1701020C]; 2017 Six Talent Peaks Endorsement Project of Jiangsu [grant number XYDXX-078].

Feng $\mathrm{Ye}$ is with the College of Computer and Information, Hohai University, Nanjing, 211100, China. He is also with the Postdoctoral Centre, Nanjing Longyuan Micro-Electronic Company, Nanjing, 211106, China (e-mail: yefeng1022@hhu.edu.cn).

Y. Chen is with Nanjing Longyuan Micro-Electronic Company, Nanjing, 211106, China (e-mail: 68151247@qq.com).

Q. Huang is with the College of Computer and Information, Hohai University, Nanjing, 211100, China (e-mail: qhuang0100@163.com). science majors' capability and development reasonably, and presents it in a visualized way. For example, when students apply for jobs, they are easier to make employers understand their specialty and ability by using visualized evaluation results aimed to show their achievements, characteristics, development approaches and so on. Either, with this kind of evaluation tools, teachers and counselors grasp students' development state and level of capacity in a visualized way directly, so as to provide corresponding learning contents and guidance, and further fulfill individualized education in a real sense.

With the rapid development and strong support of big data [1] and visualization technique [2], teaching evaluation, capability assessment and learning analysis progressively shift from the traditional empiricism to objectivity and from fuzzification to visual clarity. Big data and visualization technique can innovate a new mechanism for teachers to track, focus on, evaluate educators' leaning processes and outcomes. What's more, they will not only effectively improve the ability of computer science majors' capability assessment and display, but will provide us with the most direct, objective, accurate training foundation. However, the current research works show that this research field still requires theoretical foundations, appropriate models, effective tools, in-depth experimentations and practical implementations. Thus, this paper proposes a comprehensive index system for evaluating these students' ability, then designs and implements the visualized software tool of capability assessment based on dynamic radar chart and jitterplot.

The rest of the paper is organized as follows. The Section II describes some of the works related to our topics of interest. The comprehensive index system for evaluating computer science majors's capability is proposed in Section III. In section IV, the development and the key technology of visualization software tool is introduced. The Section V presents the use cases and discussion. At last, conclusion along with the direction for future research has been provided.

\section{RELATED WORKS}

The demand and ability of the country and society for computer science major are closely related to the goal and process of national informatization and intelligent manufacturing strategy. According to fundamental interests of the state, computer science major in institutions of higher education is required to train innovative research talents mastering basic theories and core technologies. IT enterprises usually expect students majoring in computer science become engineering talents to promote the continuous upgrading and development of software products with good capability of 
practice, sense of cooperation and learning ability. For some other application-oriented industries, they are also required to possess communication skills, ability of application practice, etc., to apply computer technology to practice. How to evaluate students' abilities of computer science majors comprehensively and reasonably become the key problem.

Currently, for the situation above, many researchers have focused on and proposed some research methods. L. J. Zheng [3] analyzed the demand structure of software talent and built the evaluation index system, and then gave a specific evaluation example. In [4], the authors proposed a multilevel fuzzy comprehensive evaluation and analytic hierarchy process to compute the evaluation weight set, which accomplishes to give comprehensive judgement to computer science department student about their practical ability. In [5], Z. H. Su applied the fuzzy logical feature mapping artificial neural network to the evaluation of the graduates' theoretical basis and application ability, and then he verified the effectiveness of the algorithm. S. B. Ren [6] proposed a teaching reform approach based on CDIO capability maturity model, and constructed the four-stage teaching pattern centered on fostering engineering capability. The works above studied the capability assessment of students' from different standpoints, but all of them did not implement the visual software tools for educators.

In [7], the author constructed an evaluation system of ability of students major in computer application in higher vocational schools, and development the software for the evaluation system. An information system of students' assessment of the capacity for a vocational school was developed and introduced in [8]. However, the evaluation indexes are presented in a very simple way for both of them. Therefore, we need to design a comprehensive index system, and then implement a visual software tool according to the index system.

To sum up, the methods of designing different evaluation indexes for computer majors are diverse, but this research field still requires theoretical foundations, appropriate models, effective tools, in-depth experimentations and practical implementations. Specifically, visual presentation can lead to a more intuitive and efficient assessment for computer majors because of the comprehensive index system.

\section{AN INDEX SYSTEM FOR EVALUATING COMPUTER SCIENCE MAJOR'S CAPABILITY}

Based on Delphi method [9], the proposed index system of computer science majors' capacity assessment can be represented by a quintuples $\mathrm{P}: \mathrm{P}=\{$ Bas, Pro, Pra, Cre, Act $\}$. Bas refers to computer science majors' basic ability in mathematics and foreign languages, which can be reflected by their grades in advanced mathematics, discrete mathematics, probability theory, linear algebra and foreign languages. Bas could be calculated by formula (1):

$$
\text { Bas }=\frac{\sum(\text { grade point } * \text { credit })_{\text {basic curriculum }}}{\sum \text { credit }}
$$

Pro refers to the professional ability measuring students' mastery of main courses in computer science, which can be reflected by grades in some courses, such as algorithms and data structures, database, programming methodology, software engineering, operating system and so on. Pro could be calculated by formula (2) :

$$
\text { Pro }=\frac{\sum(\text { grade point } * \text { credit })_{\text {professional curriculum }}}{\sum(\text { credit })_{\text {professional curriculum }}}
$$

Pra refers to the practical ability showing students' ability of practice, programming, software installation and code debugging, which can be reflected by either grades of computer operation or their participation in professional competitions, such as China Software Cup, ACM International Collegiate Programming Contest [10]-[12], etc. Pra could be calculated by formula (3):

$$
\begin{aligned}
\text { Pra }= & \frac{\sum(\text { grade point } * \text { credit })_{\text {experimental course }}}{\sum\left(\text { credit }_{\text {experimental course }}\right.} * \alpha \\
& +\sum \text { contest award } *(1-\alpha)
\end{aligned}
$$

In formula (3), the contest award of national level could be counted as 5 points, of provincial level as 3 points, and of participation as 1 point. It is consistent with five-grade making system in the course. And the coefficient $a$ can be dynamically set according to the needs of assessment. For example, when there are fewer contest award, we can set the coefficient $\alpha=1$.

Cre refers to innovation ability reflecting computer science majors' declaration of invention patents and scientific paper writing. Therefore, the calculation of innovation ability can be made in formula (4):

$$
\text { Cre }=\sum(5 * \text { num } 1+3 * \text { num } 2+1 * \text { num } 3)
$$

In formula (4), num1 represents the number of paper in SCI or EI journal article, num2 represents the number of paper in EI meeting, Chinese core periodicals and declaring invention patent, and num 3 represents the number of the common scientific articles and declaring other kind of patents. Publishing one paper in SCI, EI counts 5 points; publishing one work in EI meeting, Chinese core periodicals and declaring invention patent count 3 points; publishing the scientific article and declaring other kind of patents count 1 point. For example, if an excellent student finished two papers by his third year, and the papers were retrieved by SCI journal and EI meeting respectively, then his Cre is 8 .

In terms of the rapid progress in computer technology, it is also very important to examine and evaluate students' active learning ability $A C T$, which embodies their changes in learning process. In order to define it, we choose to use the Hale Index Valuation [13], [14] to calculate "Progressing Mark", that is, to use exponential equation to clarify the achievement and difficulty. Then, $A C T$ is assessed on the basis of the progress of higher and lower achievers, different weight of the difficulty and "Progressing Mark" accumulated in two academic years. Because distinct courses in each semester have great differences, in the actual calculation, scores could be regarded as grade point averages of professional courses and experimental classes which are used to calculate Pro and Pra, and later T-score and Progressing 
Mark could be counted with Hale index method.

Take data of two students (No.1 and No.2) selected randomly as an example (data from the educational administration system of Hohai University). From Table I, we can see No.1 has good grades in basic courses and higher scores in professional courses, showing great professional abilities; gains full marks or even the first prize in the contest, reflecting excellent performance in experimental classes and competitions; possesses 3 invention patents, revealing outstanding innovation ability and progressive active learning ability as the academic year increasing. No.2 is excellent in basis courses, but less outstanding in professional courses. She has good practical ability, but need improve further in innovation for she makes no contributions in this respect. Further, her active learning ability is stable. (see Table I).

TABLE I: THE SAMPLE OF GRADES IN COURSES AND CONTESTS OF FRESH GRADUATES OF 2008-2010 SESSIONS

\begin{tabular}{cccccc}
\hline \hline No. & $\begin{array}{c}\text { Basic } \\
\text { ability }\end{array}$ & $\begin{array}{c}\text { Professional } \\
\text { ability }\end{array}$ & $\begin{array}{c}\text { Practical } \\
\text { ability }\end{array}$ & $\begin{array}{c}\text { Innovation } \\
\text { ability }\end{array}$ & $\begin{array}{c}\text { Active } \\
\text { leaning } \\
\text { ability }\end{array}$ \\
\hline 1 & 4.02 & 4.35 & 5.0 & 3 & 14.7 \\
2 & 4.41 & 4.10 & 4.0 & 0 & 13.0 \\
\hline \hline
\end{tabular}

\section{DEVELOPMENT OF Visualzation SOFTware TOOL}

When it comes to computer science majors' capability assessment, it is difficult and not clear to show multi-attribute data with the sheet alone. For the visualized mechanism that reflects characteristics of multi-attribute data or relationships among data, radar chart [15]-[17] is one of representatives. It is organized by a number of equidistant concentric circles representing certain scores which are gradually increasing from the center to outward circles. It also consists of a sequence of spokes outward, each of which represents an evaluation index. Then, each index value is normalized processed and scaled on its axis. Next, radar chart representing and evaluating each index is obtained, after points on adjacent axes of two-dimensional plane are sequentially connected. Combining graphs and data, comprehensive evaluation method based on radar chart extracts characteristic values in the chart by nonlinear transformation of data, uses comprehensive evaluation function to calculate the evaluation function value and then reflects the comprehensive evaluation result of the object.

For comparing individual performance with peers, we choose jitterplot [18] as a visualization mechanism, which can make it easy to see how well or poorly a student performed compared to other students. In a jitterplot, it is the color more than anything else that makes the individual's ratings pop out from all the other ratings. The selected individual's dot is centered horizontally, but it is the different color that does the most to make the selected person stand out.

In order to generate the Web-based dynamic radar chart and jitterdot visualization mechanism according to students' grades achieved in each semester, Bootstrap [19], D3.js [20, [21] and Ajax [22] techniques have been mainly used. Bootstrap is a free, open-source collection of tools for creating responsive web sites and web applications. The templates of Bootstrap are based on HTML5 and CSS3, and cover navigation, typography, forms, buttons, and other web site components, as well as optional JavaScript extensions. Following the Web standard, D3.js is a visualized drawing library based on JavaScript and HTML. It manipulates documents with data and then brings data to life vividly by using HTML, SVG, and CSS, independent to any particular browser. Its display function for realizing dynamic radar charts has been embedded into the framework implemented by Bootstrap. Ajax can be used to refresh a web page dynamically, that is, to request certain operations from the server, and then to change some of web pages or prompt users' related information, etc., rather than reloading the entire page. Its essence is an asynchronous JavaScript request operation, significantly improving users' experience. Therefore, in the system, Ajax is used to obtain the evaluation value of student's capability stored by back-end in the database, then to update and display it in the front-end.

Take the radar chart for example. The key code for the radar chart is as follows.

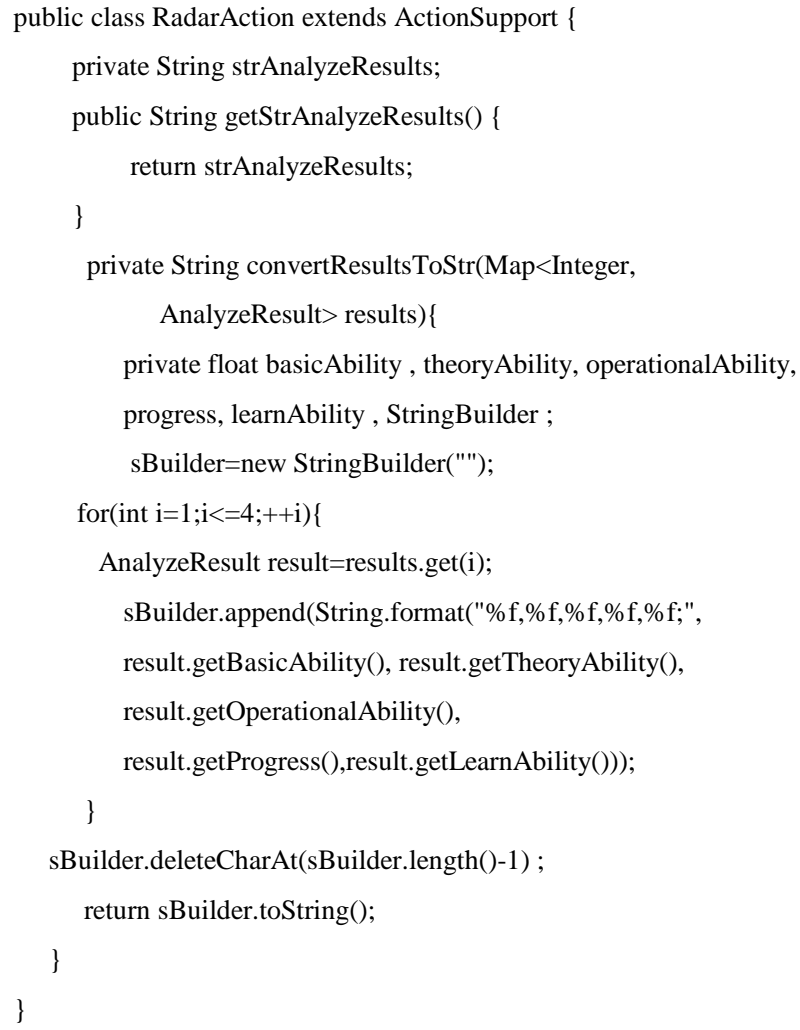

\section{CASES AND DISCUSSIONS}

Currently, scores of fresh graduates in the college have been calculated according to the evaluation index system, and the results are stored in the database. Radar chart could display one of students' capability when their names and numbers in the drop-down box are chosen and clicked. Fig. 1 shows the dynamic radar chart of one student's (No. 1) different capabilities in the first and third year, in which distinct colors are used to distinguish shapes in different academic years. It is not difficult to see that No. 1 has always maintained active learning ability, made significant progress especially in innovation ability and practical ability. However, 
due to the limited progress in basic and professional competence, teachers have to supervise his related courses in this respect.

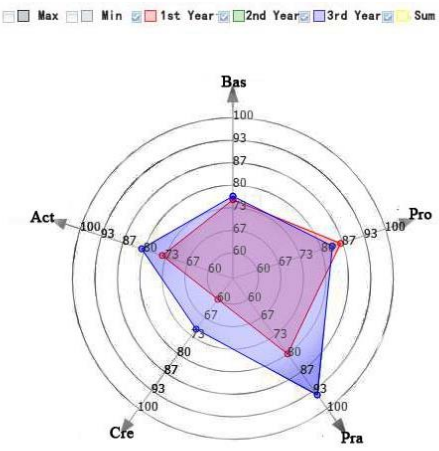

Fig. 1. Display and comparison of radar chart of one student's capability in the first and third year.

Fig. 2 shows the dynamic radar of student 2 and it reveals a dynamic radar chart of another student during undergraduate studies. In this figure, the area coverage of the radar is getting larger gradually. Apparently, the area in senior grades covers that in junior grades. Thus, it is easy to show that student 2 has made progress in all aspects during the university.

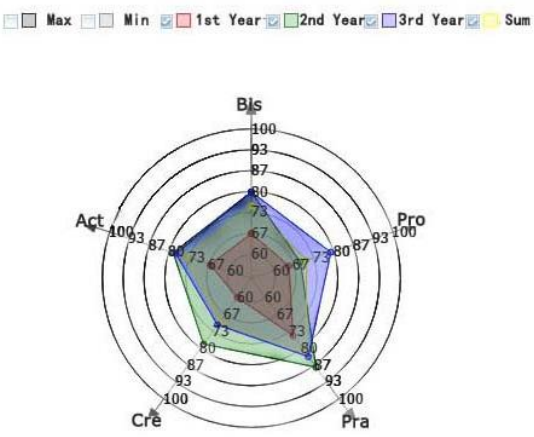

Fig. 2. Display and comparison of radar chart of another student's capability during undergraduate studie.

Fig.3. shows a student's ranking comparion with peers using jitterdot. From this jitterdot, we'll look at comparing an individual score versus the aggregate of all scores in a moment, but seeing all the dots allows presenters to see not just where they are relative to others but also just how many other people were rated.

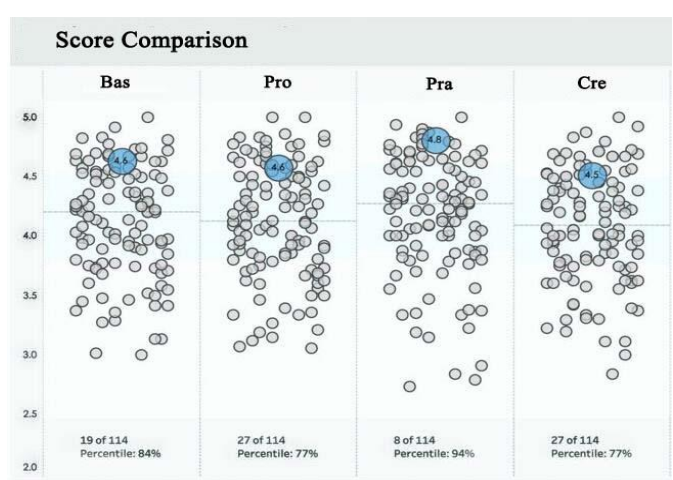

Fig. 3. The jitterdot of a student's ranking comparion with peers.
With three instantiate functions above, the evaluation index system with the display of radar chart and jitterdot allows teachers to understand each student's capability timely in each academic year, and to pay close attention to their strengths or progress. For instance, one student has a good ability to innovate, or still need great assistance in practical ability. In addition, this visual software tool provides the most direct, objective and accurate training foundation for teachers and students through comparisons of different academic years and of different students. Obviously,

\section{CONCLUSION}

A scientific evaluation system can fully understand the learning process of students, promote the overall development of students and improve teaching. Such an index system for assessing capabilities of computer science majors having been put forth, visualized software of capability assessment has been developed in collaboration with the professional firm, based on the dynamic radar chart. The visual software effectively evaluates and displays capabilities of computer science students and offers more direct, objective, accurate data results. On the basis of current research, it is proposed to further improve big data processing mechanism, function of analysis and comparison, etc., to optimize users' experience, to provide more help for teaching and students recommendation.

In future, as the number of students and data increases, we will adopt Apache Spark [23] as the big data processing framework to upgrade existing visual software tool. Its strong data processing capability and abundant machine learning algorithms will be easy to deal with more query requests and data analysis requirements.

\section{REFERENCES}

[1] M. Chen, "Visualization analysis of big data," Computer Education, vol. 5, pp. 94-97, May 2015.

[2] Y. M. Hu and A. A. Liang, "Application of different types of data visualization method in education research," Educational Measurement and Evaluation, vol. 8, pp. 10-23, August 2016.

[3] L. J. Zheng and Y. C. Ren, "A software capability evaluation method for computer majored students," Computer Technology and Development, vol. 6, pp. 233-240, June 2013.

[4] X. L. Ren, "The study and exploration of practice and application computer personnel training mode," Microcomputer Applications, vol. 30, no. 12 , pp. 23-25, May 2014

[5] Z. H. Su, "Research on the evaluation of undergraduates' theoretical foundation and application skills based on FLFM clustering algorithm," M.S. thesis, Northeast Normal Univ., Changchun, China, 2014.

[6] S. B. Ren, Z. G. Hu, and B. Wu, "Teaching reform and practice on fostering engineering capability for the undergraduate student," in Proc. 2011 International Conference on Computing, Information and Control, pp. 246-251, Part 4, 2011.

[7] H. H. Xing, "The study of evaluation system of ability of students major in computer application in higher vocational schools," M.S. thesis, Shandong Normal Univ., Jinan, China, 2016.

[8] X. T. Tang, "The design and implementation of student ability evaluation system under the environment of J2EE and Android," M.S. thesis, Guangxi Univ., Nanning, China, 2015.

[9] W. Xing, "Evaluation of the quality of entrepreneurship students," M.S. thesis, Jilin University, Changchun, China, 2011.

[10] Z. F. Kuang, S. J. Yu, and W. M. Yang, "The role of ACM/ICPC on training innovative talents in information science," Computer Education, vol. 3, pp. 4-6, March 2013.

[11] L. Lu, Y. Chen, and G. L. Gou, "The research and practice of training model on learning ability based on ACM," Computer Education, vol. 7, pp. 59-65, July 2013. 
[12] F. Ye, S. Y. Wu, X. J. Zhang, and L. Li, "The research on computer science majors' capability cultivation relying on academic competitions," Computer Education, vol. 3, pp. 43-47, March 2017.

[13] Q. Y. Jiang, J. X. Xie, and J. Ye, Mathematical Model, 4th ed. Beijing, CHN.: Higher Education Press, 2011, ch.3.

[14] X. H. Cui, D. Wang, and F. K. Yu, "Mathematical model of evaluating students' learning," The Science Education Article Collects, vol. 2, pp. 42-43, February 2010.

[15] H. J. Cheng, "Visual evaluation of warfighting capability of air defense weapon system based on radar chart method," Fire Control \&Command Control, vol. 40, no. 5, pp. 29-31, May 2015.

[16] Y. Fu and D. Y. Fang, "Applied research of radar chart method in comprehensive evaluation," Statistics and Decision, vol. 23, no. 24, pp 176-178, December, 2007.

[17] H. L. Zheng, C. Liu, and D. N. Zhai, "Comprehensive evaluating method based on radar-graph," Journal of Nanjing University of Posts and Telecommunications (Natural Science), vol. 21, no. 2, pp. 75-79, June 2001.

[18] S. Wexler, J. Shaffer, and A. Cotgreave, The Big Book of Dashboards: Visualizing Your Data Using Real-World Business Scenarios, Hoboken: Wiley, 2017, ch. 3.

[19] L. F. Sikos, Web Standards: Mastering HTML5, CSS 3, and XML, Berkeley, CA.: Apress, 2014, ch. 11, pp. 397-398.

[20] M. Dewar, Getting Started with D3, Sebastopol: O'Reilly Media, 2012, ch. 1.

[21] M. Scott, Interactive Data Visualization for the Web, Sebastopol: O’Reilly Media, 2013, ch. 2.

[22] M. Jeremy and W. Paul, Beginning JavaScript, $5^{\text {th }}$ ed. Beijing, CHN.: Tsinghua University Press, 2016, ch. 1.

[23] H. Karau, A. Konwinski, P. Wendell, and M. Zaharia, Learning Spark, Sebastopol, CA: O’Reilly Media, 2015, ch. 11.

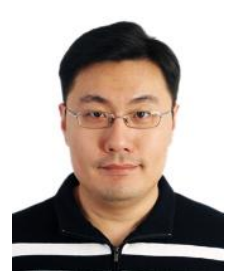

Feng Ye was born in Jinan, Shandong province, China, in October 1980. He received the B. Sc. degree in computer science from Hohai University in 2003, the master degree of computer application technology from Hohai University in 2007 and the $\mathrm{Ph}$. D. degree in computer science from Nanjing University of Aeronautics and Astronautics in 2016.

Since 2003, he is with Hohai University, Nanjing, China, where he serves as an assistant and lecturer successively in college of computer. Since Dec. 2016, he becomes a post-doctor in Nanjing Longyuan Micro-Electronic Company. He has published around 30 technical articles and holds six Chinese patents. His main research interests include big data, machine learning and cloud computing.

Dr. Ye is a member of the CCF (China Computer Federation), and the candidate of 2017 Six Talent Peaks Endorsement Project of Jiangsu.

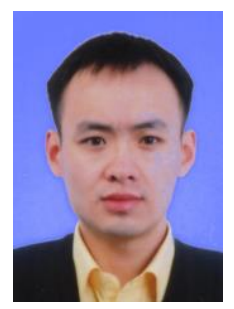

Yong Chen was born in Suining, Sichuan Province, China, in October 1977. He received the B. Sc. degree in economics from Peking university, China, in 2000 , and the Master degree of public administration from Shanghai Jiaotong University in 2007.

Since 2011, he founded Longyuan microelectronics technology co. LTD, and became chairman of the company. He has published around 10 technical articles and holds more than forty Chinese patents and software copyrights. His main research interests include IoT, smart agriculture and cloud computing.

Mr. Chen was the candidate of 2014 Six Talent Peaks Endorsement Project of Jiangsu, and Jiangsu "333"engineering training personnel in the same year. In 2015, he became one of the specialists who enjoy the State Council Special Allowance. In 2017, he was the gainer of the second batch of national ten thousand plan of science and technology innovation talents.

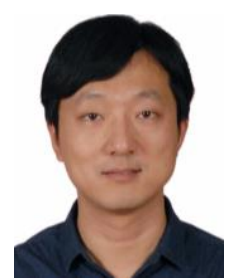

Qian Huang was born in Haian, Jiangsu Province, China, in October 1981. He received the B. Sc. degree in computer science from Nanjing University, China, in 2003 , and the Ph. D. degree in computer science from the Institute of Computing Technology, Chinese Academy of Sciences, in 2010.

From Mar. 2008 to Mar. 2009, he was a fulltime research intern at the Communication Technology Lab of Intel China Research Center, Beijing, China. From 2010 to 2012, he was a deputy technical manager of Mediatek (Beijing) Incorporation, Beijing, China. Since Dec. 2012, he is with Hohai University, Nanjing, China, where he serves as an ASSOCIATE PROFESSOR in computer science. He has published two monographs, four translated books and around 30 technical articles. He holds two US patents and five Chinese patents. His main research interests include multimedia data processing, machine learning and cloud computing.

Assoc. Prof. Huang is a member of the CCF (China Computer Federation) Technical Committee on Multimedia Technology, a member of CSIG (China Society of Image and Graphics) Technical Committee on Multimedia and a member of the JCS (Jiangsu Computer Society) Technical Committee on Cloud Computing. 